Article

\title{
Effects of Whole-Body Electromyostimulation on Physical Fitness in Postmenopausal Women: A Randomized Controlled Trial
}

\author{
Alvaro Pano-Rodriguez ${ }^{1, *}$, Jose Vicente Beltran-Garrido ${ }^{2} \mathbb{D}$, Vicenç Hernandez-Gonzalez ${ }^{1} \mathbb{D}$ and \\ Joaquín Reverter-Masia ${ }^{1}$ \\ 1 Research Group Human Movement, University of Lleida, Av. de l'Estudi General, n.4 E-25001 Lleida, Spain; \\ vicens_h_g@didesp.udl.cat (V.H.-G.); reverter@didesp.udl.cat (J.R.-M.) \\ 2 EUSES Health and Sport Sciences School, Rovira i Virgili University, C/Sebastià Joan Arbó, 2, 43870 Amposta, \\ Spain; jose.vicente@euseste.es \\ * Correspondence: alvarodepano@didesp.udl.cat; Tel.: +346-4954-6894
}

Received: 11 February 2020; Accepted: 6 March 2020; Published: 8 March 2020

check for updates

\begin{abstract}
Whole-body electromyostiulation (WB-EMS) has experienced a boom in recent years, even though its effectiveness is controversial. A sedentary lifestyle is deeply rooted in the European population, mainly in the elderly. This experimental study analyzed the impact of WB-EMS on the physical fitness of postmenopausal women. Thirty-four healthy sedentary women between 55 and 69 years followed an experimental design pre-post-test. Both groups conducted a ten-week aerobic and strength training program. The experimental group overlaid the WB-EMS during exercise. At the end of the intervention, both groups improved upper and lower body strength, lower extremity flexibility, agility, and speed levels $\left(p_{\text {Bonferroni }}<0.05\right)$. Significant interactions were observed at upper and lower body strength, agility, speed, and cardiovascular endurance $(p<0.05)$. The WB-EMS group scored better agility than the control group at the end of the intervention $\left(p_{\text {Bonferroni }}<0.05\right)$ and was the only group that improved cardiovascular endurance. WB-EMS shows a favorable isolate effect on the development of dynamic leg strength, agility, and cardiovascular endurance but did not in dynamic arm strength, gait speed, balance, or flexibility of postmenopausal women.
\end{abstract}

Keywords: whole-body electrical muscle stimulation; whole-body electrostimulation; physical exercise; aging; public health

\section{Introduction}

It has been established that physical activity plays a fundamental role in the prevention and treatment of the inconveniences associated with advanced age, such as chronic diseases, functional limitation, and dependence. Consequently, physical activity is a key element in the improvement in life quality [1-3]. Therefore, exercise is considered an appropriate medicine in the treatment of various chronic diseases [4]. However, being a resource of enormous potential, it is in critical disuse as a preventive strategy [5]. Postmenopausal women, in particular, are associated with losses in strength and power [6] along with weight and fat mass gains [7,8], which may partly result from decreased physical activity time $[9,10]$, hence leaving postmenopausal women at a heightened risk of developing adverse health outcomes.

High-intensity training has shown great effectiveness in acquiring fitness in the elderly, both in the exercise of strength [11-14] and endurance [15,16]. For this reason, new training methodologies that facilitate a high intensity of exercise have acquired great relevance in recent years. The functional electrical electrostimulation (FES) technique called whole-body electromyostimulation (WB-EMS) is one such case. 
FES is based on the application of a rectangular, biphasic, and symmetrical current electric pulse to the motor unit by placing electrodes on the skin to activate the skeletal muscle. FES techniques are diverse and have different aims. On one side, electrotactile electrostimulation provides sensations by passing a low-intensity electric current to stimulate afferent nerve, which is very useful in hand prosthesis for better manipulation performance [17]. On another side, local electrical stimulation entails the placement of little electrodes on the motor unit, applying a current intense enough to activate the muscle. Its use is aimed at musculoskeletal rehabilitation [18] or even improvement in the performance in sports [19]. Finally, the WB-EMS consists of the application of an electrical pulse by using a suit in which large surface electrodes are strategically placed. The equipment generally allows the activation of thighs, arms, buttocks, abdomen, chest, lower back area, upper back area, wide back, and with two auxiliary channels of free choice with a total electrode area of $2800 \mathrm{~cm}^{2}$ [20]. Different authors found that WB-EMS training has the same effectiveness in improving physical fitness as traditional and high-intensity resistance training without WB-EMS [21-23]. The suitability of using WB-EMS as an intensity method to improve the physical condition of older women has been raised since it guarantees sufficient effort in those people unable or unwilling to do so on their own initiative [24]. Previous studies analyzed the effects of WB-EMS on the health of elders finding improvements in cardiometabolic risk and sarcopenia [23-29]. Besides, in young people, the WB-EMS has established itself as an effective method of physical conditioning, achieving improvements in VO2max, aerobic threshold, anaerobic threshold, and running economy [30] and in the maximum isometric strength of leg extenders, vertical jump, and strength hand grip [21,24,25,29-31].

In addition to the aforementioned strength and endurance variables, several interesting aspects of physical condition, such as balance, flexibility, or agility, are commonly studied to draw conclusions regarding the influence of exercise on the health and functional capacity of the elderly [32]. However, the influence of the WB-EMS has not been analyzed so far in these variables. Therefore, the objective of this study is to analyze from a broad and multivariable perspective the influence of a ten-week WB-EMS training program on the physical performance of postmenopausal women.

\section{Materials and Methods}

\subsection{Experimental Approach}

The study was designed as a blinded two-arm randomized trial with parallel-groups. The reporting was done following the CONSORT guideline for standard items in interventional trials [33].

Participants were randomly distributed by a computer random number generator [34] in the experimental group called voluntary exercise with WB-EMS (EX + WB-EMS, $\mathrm{n}=17$ ) or the control group called voluntary exercise $(E X, n=17)$. The $E X+W B-E M S$ group conducted a resistance strength training program with superimposed WB-EMS, while the EX group performed only resistance strength training. Participants were evaluated with the Exercise Network Test (EXERNET) [33] at the beginning and the end of the 10 weeks of intervention (See Figure 1). 


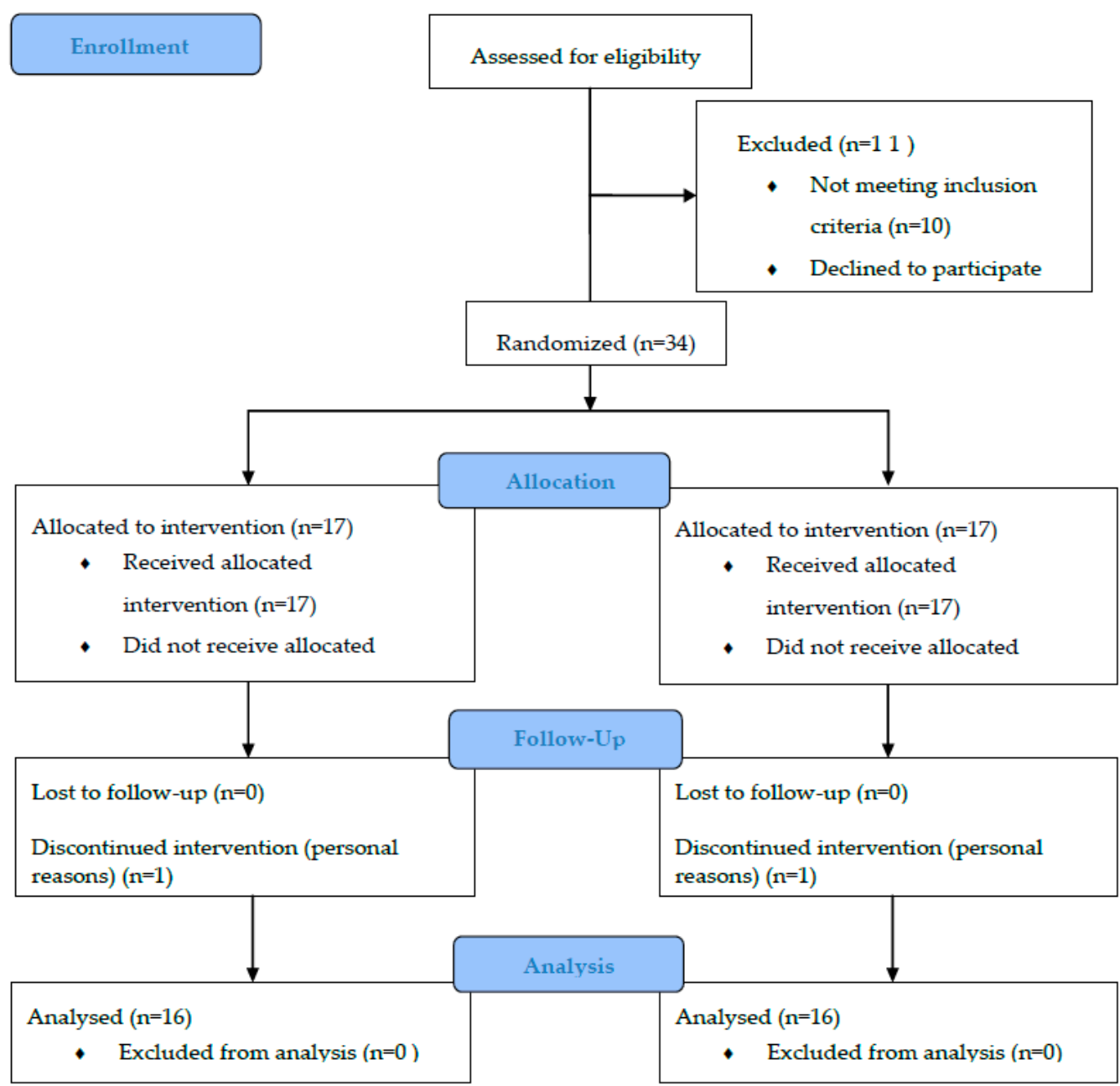

Figure 1. CONSORT flow diagram. This figure shows the flow of participants through the trial according to the criteria recommended in the CONSORT guidelines.; EX = Voluntary exercise group; $\mathrm{EX}+\mathrm{WB}-\mathrm{EMS}=$ Voluntary exercise with whole-body electromyostiulation (WB-EMS).

\subsection{Participants}

Thirty-four postmenopausal untrained women living in Lleida (Spain) voluntarily participated in the study, which was conducted from September 2018 to April 2019. The recruitment period was from June to August 2018. They were contacted by a phone call to be informed about the nature of the project. All of them were invited to attend an informational meeting where more details were given on the benefits and possible risks that their participation in the project might entail. The subjects who showed interest in participation were recruited according to the inclusion criteria. Inclusion criteria were as follows: 1) Participants did not suffer any injury or illness that could interfere with the correct execution of the training program. Reported contraindications for WB-EMS intervention (i.e., total endoprosthesis, abdomen/groin hernia, epilepsy, and cardiac arrhythmia), 2) sedentary status according to the scales provided by the Eurobarometer [35], 3) postmenopausal status (detailed below in a separated section). They were allocated and informed about their assigned arm by a phone call, which was made by an external collaborator. The characteristics of the sample (mean \pm SD) are shown in Table 1. At the end of the study, there was a withdrawal in each group, both of them due to personal reasons. All participants were informed about the details of the study and signed an informed consent form before starting the investigation. The study was conducted in accordance with the Declaration of Helsinki, and the protocol was approved on 12/01/2016 by the Ethics Committee of the Arnau of Vilanova's University Hospital, Lérida, (Spain) (CEIC-1701). Trial registration: ISRCTN15558857 last edited: 02/12/2019. 
Table 1. Sample's characteristics.

\begin{tabular}{ccccc}
\hline Variable & $\begin{array}{c}\text { Total } \\
(\boldsymbol{n}=\mathbf{3 4})\end{array}$ & $\begin{array}{c}\text { EX + WB-EMS } \\
(\boldsymbol{n}=\mathbf{1 7})\end{array}$ & $\begin{array}{c}\text { EX } \\
(\boldsymbol{n}=\mathbf{1 7})\end{array}$ & $\boldsymbol{p}$-Value \\
\hline Age (years) & $61.4 \pm 4.0$ & $63.1 \pm 3,42$ & $59.7 \pm 3,82$ & 0.011 \\
Body mass $(\mathrm{kg})$ & $67.4 \pm 10.8$ & $67.7 \pm 10.1$ & $67.1 \pm 10,8$ & 0.866 \\
Height $(\mathrm{cm})$ & $158.3 \pm 5.3$ & $159.9 \pm 5.2$ & $156.7 \pm 5.0$ & 0.614 \\
Body mass index $\left(\mathrm{BMI}, \mathrm{kg} / \mathrm{m}^{2}\right)$ & $29.9 \pm 4.1$ & $26.5 \pm 4.1$ & $27.3 \pm 4.2$ & 0.220 \\
\hline
\end{tabular}

$\mathrm{EX}=$ Voluntary exercise group; EX + WB-EMS = Voluntary exercise with whole-body electromyostiulation (WB-EMS).

\subsection{Menopause Status}

Hormone assessments were performed from fasting serum samples taken between 8:00 and 10:00 a.m. The serum was separated by centrifugation for $10 \mathrm{~min}$ at $2200 \times \mathrm{g}$. Systemic FSH levels were immunoassayed using IMMULITE 2000 XPi (Siemens Healthcare Diagnostics, Camberly, UK). Participants' menopause status was determined based on the self-reported menstrual cycle.

Applying the categorization of Kovanen et al. [36], subjects were postmenopausal if no menstrual bleeding during the past 6 months and following cut values were applied FSH $>30 \mathrm{IU} / \mathrm{L}$. Participants self-reported their health problems, gynecologic status, and use of medications.

\subsection{Interventions}

Both groups trained with a frequency of 2 weekly sessions during a total of a 10-week program. They had $48 \mathrm{~h}$ of rest between sessions. The EX + WB-EMS group trained on Mondays and Thursdays, while the EX group trained on Tuesdays and Fridays. Both groups performed the same program consisting of endurance tasks and resistance strength exercises, but the EX + WB-EMS group also had a superimposed WB-EMS implemented during the training. The complete electrostimulation equipment, consisting of the suit and the electrostimulator device, does not weigh more than $1.5 \mathrm{~kg}$ and does not entail any limitation or discomfort for the movement of the body. The training protocols were supervised by two instructors who had graduated in physical activity and sports sciences with wide experience in WB-EMS training. Participants were asked not to make physical efforts outside the training program.

Training protocol: The sessions lasted $40 \mathrm{~min}$. Participants performed a 10-min warm-up by walking on a treadmill at a moderate speed. Subsequently, participants performed the resistance training protocol (see Figure 2), which consisted of performing 3 multi-articular exercises involving push and pull actions (squat, deadlift, and bench press) as Aragão-Santos et al. [37] suggest as a recommended option in older people.

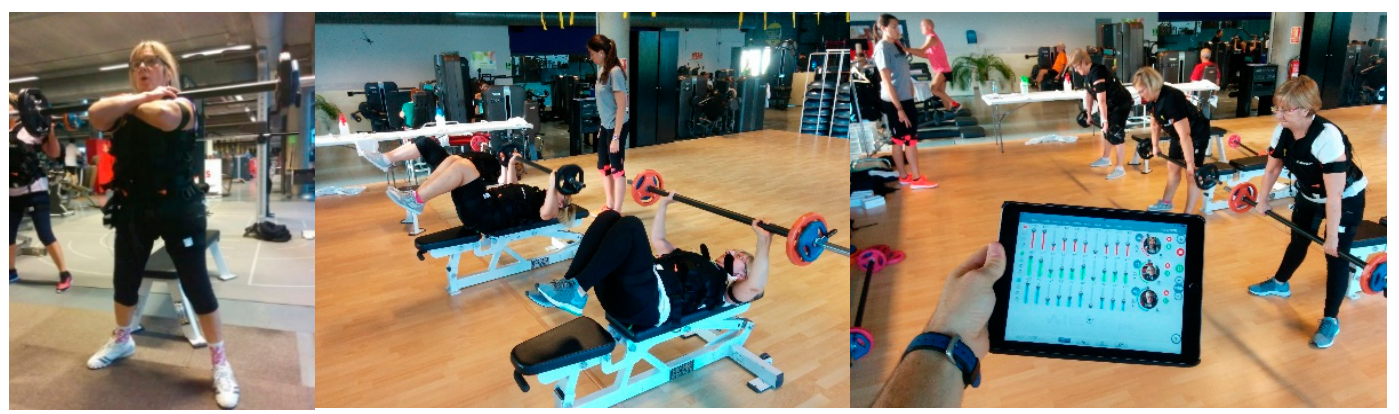

Figure 2. Strength training program exercises.

The resistance training protocol lasted $10 \mathrm{~min}$ divided into 2 blocks of $5 \mathrm{~min}$. One block consisted of 10 sets of each exercise. Sets were composed of 2 repetitions with $2 \mathrm{~s}$ of eccentric and $1 \mathrm{~s}$ of concentric phase ( $6 \mathrm{~s}$ in total per set). Between repetitions, participants had $4 \mathrm{~s}$ of rest. 
The intensity of the resistance training was $40 \%$ of the one-repetition maximum (1RM) obtained by an indirect measurement test [38]. Following the line of Wirtz et al. [39], the absolute load was increased by $5 \%$ every two weeks to apply the principle of progressive overload. After strength exercises, participants performed a 10-min cardiovascular work on a treadmill, at a constant individualized speed, obtained from the talk test [40] (i.e., the highest speed they could walk while talking). The intensity of cardiovascular training was increased by 5\% every week. Finally, the participants performed 10 min of stretching of the muscles of the whole body as a cooldown.

At the end of each session, a scale was presented [41] with a range of 6 (no exertion at all) to 20 (maximal exertion) in which the participants of both groups recorded their internal training load perception. The assessment was always close to 15 (Hard).

WB-EMS intervention: The EX + WB-EMS group performed resistance strength training with superimposed WB-EMS. A rectangular, bipolar compensated current of $6 \mathrm{~s}$ duration and $4 \mathrm{~s}$ rest was applied with a Wiemspro ${ }^{\circledR}$ electrostimulator (Malaga, Spain) (Figure 3). The decision to use the Wiemspro ${ }^{\circledR}$ device in this study was due to the fact that, unlike other electromyostimulators, it is very light and short, which makes it portable. Due to this, it is possible to wear the device attached to the body. This characteristic means that it does not impede or restrain the body's movements.

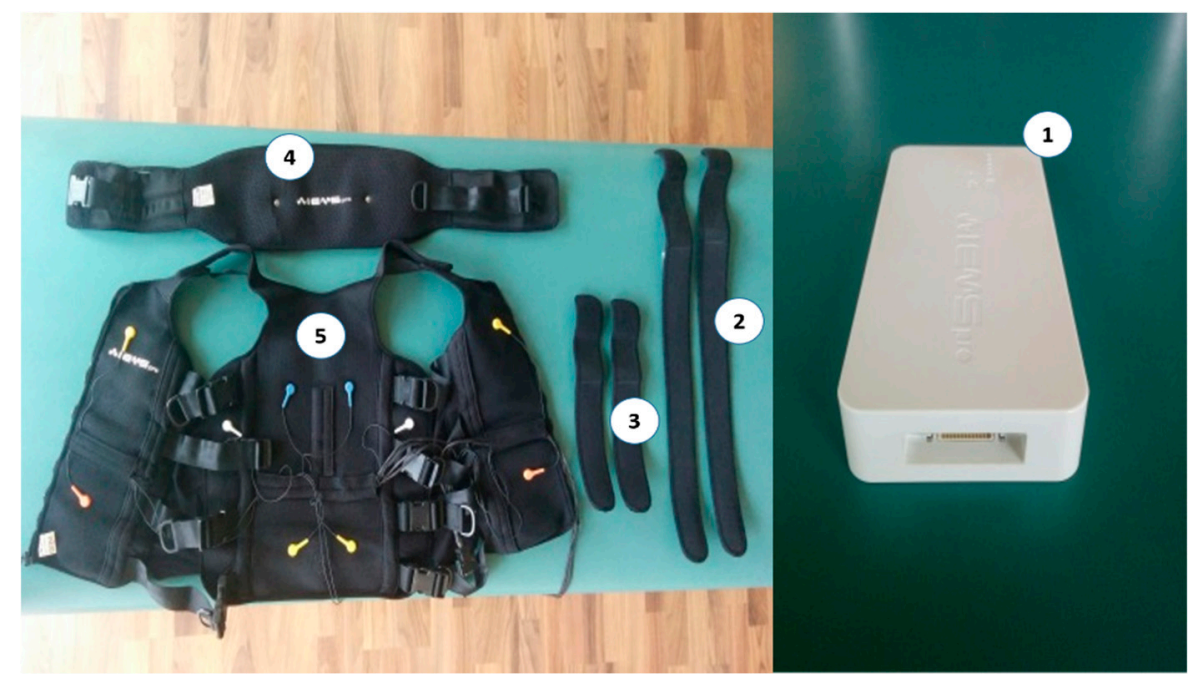

Figure 3. Wiemspro equipment. (1) The electromyostimulator device, (2) Strap electrodes for the thighs, (3) Strap electrodes for the arms, 4) Belt with electrodes for the buttocks, (5) Vest with electrodes for the abdomen, chest, and back area.

Since there is evidence that a current frequency $\geq$ of $50 \mathrm{~Hz}$ is necessary to cause adaptations in strength training [42], during the strength exercises, a frequency of $55 \mathrm{~Hz}$ was applied with a $60 \%$ duty cycle (pulse width: leg and glute $350 \mu \mathrm{s}$, lumbar, rectus abdominis and latissimus dorsi $300 \mu \mathrm{s}$, trapezius $250 \mu \mathrm{s}$, chest $200 \mu \mathrm{s}$, and arms $150 \mu \mathrm{s}) 800 \mathrm{~ms}$ ascent ramp and descent ramp 500 ms $[43,44]$. Taking into account the effectiveness of low-frequencies of electrostimulation on the aerobic capacity [45], during cardiovascular training on the treadmill, the current applied was $7 \mathrm{~Hz}$ with a duty cycle of $100 \%$.

The fat modifies the transmission of the electrical stimuli into muscle [46]. Thus, current intensity had to be normalized in the WB-EMS training. Following a procedure similar to that of Kemmler $y$ col [25], four levels of intensity perception of the electrical current (IPC) were established on a scale from 1 to 10 to control the perceived intensity produced by the application of the WB-EMS in the participants, being from 1 to 4 (mild), from 4 to 6 (moderate), from 6 to 8 (intense), and from 8 to 10 (pain). Participants gave constant information on the IPC during the session. The first two weeks, training was conducted at a "moderate" IPC level to promote familiarization and adaptation to the WB-EMS. The remaining 8 weeks of the intervention, the intensity increased to an "intense" IPC level. 
When the same intensity level is maintained during a WB-EMS session, the IPC decreases over time. Hence, the intensity of the current increased gradually within the same session, without exceeding the level of IPC corresponding to that session.

\section{Harms}

Adverse events, including physical injuries, were monitored by the instructors of the intervention and the responsible staff of the assessments and documented through the facility's incident reporting process.

\subsection{Patient and Public Involvement}

Patients and the public were not directly involved in the design of the study. The intervention was chosen based on studies reporting the drastic decline of power on postmenopausal women [6] due to hormonal changes and sedentary behaviors $[7,8,47]$. Study results will be disseminated through patients and study participants through our institution's social media platform.

\subsection{Assessments}

The assessments were carried out during the week before the training began (pre-test) and the week after the end of the intervention (post-test) in the sports center Ekke, located in Lleida (Spain). The data were recorded in a spreadsheet that was stored in an encrypted USB memory by an external collaborator, to guarantee the privacy of the participants. A blinded statistician had access to the final dataset of the study. He assessed the safety and validity of the research data. Participants were asked not to take any stimulants before assessments to avoid their influence on the results.

The evaluation of the physical fitness was carried out by the EXERNET Battery consisting of 8 tests modified and previously adapted from the "Senior Fitness Test Battery" and "Eurofit Testing Battery" [48].

- Balance: "Flamingo test". Participants started standing, with both feet on the ground. After the signal, they tried to stand on the sole of one foot. The time that the subject was able to stay in that posture up to a maximum of sixty seconds was recorded. The test was performed alternately, twice with each leg, and the best attempt of the four was registered.

- Leg strength: "Chair Stand Test". The participant started from a sitting position with her arms crossed and the palms of her hands resting on her shoulders. The number of times she was able to get up and sit in $30 \mathrm{~s}$ was registered. The test was performed only once.

- Arm strength: "Arm Curl Test". Participants sat on a bench holding $2.5 \mathrm{~kg}$. The maximum number of elbow flexo-extension that the participant was able to execute in $30 \mathrm{~s}$ was registered. The test was performed once with each arm.

- Legs flexibility: "Chair Sit-and-Reach Test". Participants began the test sitting, with one leg extended and the heel resting on the floor, while her hands were directed towards the toes of that leg. The existing distance, positive or negative, in centimeters, between the fingers and toes was measured. The test was performed once with each leg.

- Arms Flexibility: "Back Scratch Test". The participant placed a hand over the shoulder of that same arm, and the opposite hand from the bottom up, trying to touch each other. The participant tried to touch or overlap the fingers of both hands. The distance in centimeters (positive or negative) between the fingertips of each hand was measured. The test was carried out twice, once with each arm.

- Agility: "8-Foot Up-and-Go Test". From a sitting position, the seconds that the participant took to get up, walk to a cone located $2.45 \mathrm{~m}$, go around it, and sit down again were measured. The test was performed twice with at least one-minute rest between repetitions, and the best result was recorded.

- Speed: "Brisk Walking Test". The time taken for each participant to walk $30 \mathrm{~m}$ was measured. Two repetitions were performed with a minute of rest between them. The best of both results was recorded. 
- Cardiovascular resistance: "6-Minute Walk Test". In a circuit of $46 \mathrm{~m}$ delineated by cones, the meters that each participant was able to cover walking for 6 min were registered.

\subsection{Statistical Procedures}

Data are presented in mean \pm standard deviation (SD). The assumption of normality was assessed, exploring the $Q-Q$ plots and histogram of residuals. The homogeneity assumption was checked using the Levene's test. The effectiveness of interventions was assessed by a 2-way mixed ANOVA. Group intervention ("EX+WB-EMS", "EX") was included as between-subject factor, time ("Pre", "Post") was included as the repeated with-in subject factor, and group $\mathrm{x}$ time was included to account for the interaction effects. Whenever a significant main effect or interaction was observed, Bonferroni's post-hoc correction was used to aid interpretation. When baseline values differed between groups, ANCOVA analysis, adjusting by the corresponding value of the parameter at baseline $[49,50]$, were used to test the effectiveness of the intervention on dependent variables. The statistician was blind to both groups during data analyses. The significance level was set at $\alpha=0.05$ for all tests. All statistical analyses were performed in JASP (JASP Team (2019). JASP (version 0.11.1) [Computer software] University of Amsterdam, the Netherlands).

\section{Results}

The spreadsheet is available at https://osf.io (Effects of whole-body electromyostimulatin on physical fitness in postmenopausal women: a randomized controlled trial) (see Supplementary Materials). The summary statistics of the effectiveness of interventions is shown in Table 2.

Table 2. Summary of mixed ANOVA procedure results.

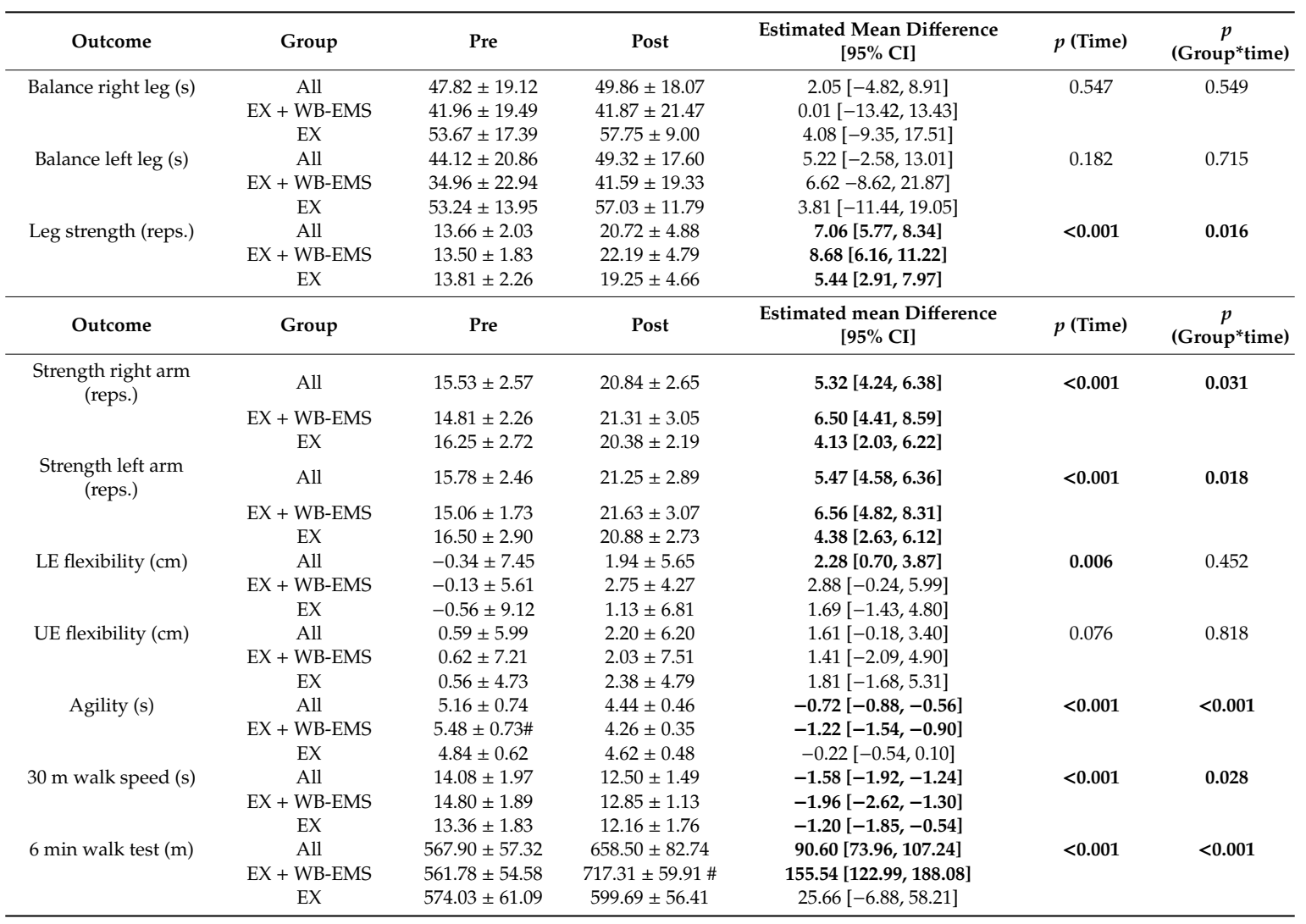

Data are presented as mean \pm SD. LE: Lower Extremity. UE: Upper extremity. WB-EMS: Whole-body electromyostiulation. EX + WB-EMS: Voluntary exercise with WB-EMS; EX: Voluntary exercise group; Significant mean differences and $p$-values $(p \leq 0.05)$ are shown in bold; \# $p_{\text {Bonferroni }} \leq 0.05$ different to EX group values. 


\section{- $\quad$ Balance right leg}

The results showed a non-significant main effect of time $\left(p=0.547, \eta^{2} p=0.01\right)$ and interaction $(p=$ $\left.0.549, \eta_{p}^{2}=0.01\right)$.

\section{- $\quad$ Balance left leg}

Data revealed a non-significant main effect of time $\left(p=0.182, \eta^{2} p=0.06\right)$ and interaction $\left(p=0.715, \eta^{2} p\right.$ $=0.01)$.

\section{- $\quad$ Leg strength}

The results showed a significant main effect of time $\left(p<0.001, \eta^{2} p=0.81\right)$ and interaction $(p=0.025$, $\left.\eta^{2}{ }^{2}=0.18\right)$. Post-hoc tests revealed significant mean difference between pre- and post-tests of both groups (EX + WB-EMS: 8.68 repetitions 95\% CI [6.16, 11.22], $p_{\text {Bonferroni }}<0.001$; EX: 5.44 repetitions 95\% CI $\left.[2.91,7.97], p_{\text {Bonferroni }}<0.001\right)$. However, non-statistically significant between-groups differences were shown in either pre-test or post-test (pre-test: 0.31 repetitions $95 \% \mathrm{CI}[-3.23,3.86], p_{\text {Bonferroni }}=$ 1.000; post-test: -2.94 repetitions $95 \%$ CI $\left.[-6.48,0.61], p_{\text {Bonferroni }}=0.162\right)$.

\section{- $\quad$ Strength right arm}

Data revealed a significant main effect of time $\left(p<0.001, \eta^{2}{ }_{p}=0.77\right)$ and interaction $\left(p=0.031, \eta^{2}=\right.$ 0.15). Post-hoc tests showed a significant mean difference between pre- and post-tests of both groups (EX + WB-EMS: 6.50 repetitions 95\% CI [4.41, 8.59], p ponferroni $<0.001$; EX: 4.13 repetitions 95\% CI $\left.[2.03,6.22], p_{\text {Bonferroni }}<0.001\right)$. However, non-statistically significant between-groups differences were reported in either pre-test or post-test (pre-test: 1.44 repetitions $95 \% \mathrm{CI}[-1.06,3.93], p_{\text {Bonferroni }}=0.723$; post-test: -0.94 repetitions $95 \%$ CI $[-3.43,1.56]$, $\left.p_{\text {Bonferroni }}=1.000\right)$.

- $\quad$ Strength left arm

The results showed a significant main effect of time $\left(p<0.001, \eta^{2} p=0.84\right)$ and interaction $(p=0.018$, $\left.\eta^{2}{ }^{2}=0.17\right)$. Post-hoc tests revealed a significant mean difference between pre- and post-tests of both groups (EX + WB-EMS: 6.56 repetitions 95\% CI [4.82, 8.31], p Bonferroni $<0.001$; EX: 4.38 repetitions 95\% CI $\left.[2.63,6.12], p_{\text {Bonferroni }}<0.001\right)$. However, non-statistically significant between-groups differences were shown in either pre-test or post-test (pre-test: 1.44 repetitions $95 \% \mathrm{CI}[-1.16,4.03], p_{\text {Bonferroni }}=$ 0.800; post-test: -0.75 repetitions $\left.95 \% \mathrm{CI}[-3.34,1.84], p_{\text {Bonferroni }}=1.000\right)$.

\section{- $\quad$ Lower extremity flexibility}

Data revealed a significant main effect of time $\left(p<0.006, \eta^{2} p=0.22\right)$. Post-hoc tests showed a significant mean difference between pre- and post-tests $\left(2.28 \mathrm{~cm} \mathrm{95 \%} \mathrm{CI}[0.70,3.86], p_{\text {Bonferroni }}=0.006\right)$. However, a non-significant interaction $\left(p=0.452, \eta^{2} p=0.02\right)$ was reported.

\section{- $\quad$ Upper extremity flexibility}

The results showed a non-significant main effect of time $\left(p=0.076, \eta^{2} p=0.10\right)$ and interaction was reported $\left(p=0.818, \eta^{2} p=0.00\right)$.

\section{- $\quad$ Agility}

Data revealed a significant main effect of time $\left(p<0.001, \eta^{2} p=0.73\right)$. Post-hoc tests showed a significant mean difference between pre- and post-tests (-0.72 s 95\% CI [-0.96, -0.47], $\left.p_{\text {Bonferroni }}<0.001\right)$. A statistically significant interaction $\left(p<0.001, \eta^{2} p=0.57\right)$ was obtained. Post-hoc tests revealed a significant mean difference between pre- and post-tests of the EX + WB-EMS group (-1.22 s 95\% CI $\left.[-1.54,-0.90], p_{\text {Bonferroni }}<0.001\right)$ but not in the EX group $\left(-0.22 \mathrm{~s} 95 \% \mathrm{CI}[-0.54,0.10], p_{\text {Bonferroni }}=0.391\right)$. 
Statistically significant between-groups differences were shown in pre-test $(0.64 \mathrm{~s} 95 \% \mathrm{CI}[-1.20,-0.09]$, $\left.p_{\text {Bonferroni }}=0.015\right)$ but not in post-test $\left(0.36 \mathrm{~s} 95 \% \mathrm{CI}[-0.19,0.92], p_{\text {Bonferroni }}=0.457\right)$.

Analysis examining differences in agility scores at the end of the post-test among EX + WB-EMS versus EX groups, adjusting by the corresponding value of the agility score at baseline, are displayed in Figure 4. At the post-test, participants in the EX + WB-EMS group showed a better agility score than their peers in the EX group $(-0.67 \mathrm{~s} 95 \% \mathrm{CI}[-0.89,-0.44], p<0.001)$.

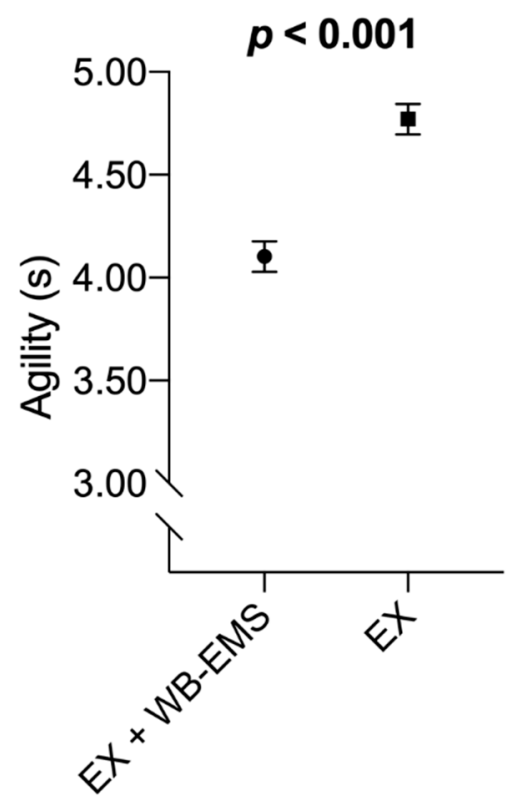

Figure 4. Analysis of covariance assessing differences in vertical agility at the end of the post-test among both groups. Estimated mean and 95\% confidence intervals (CIs; error bars) represent values after adjusting by the corresponding value of the agility test at baseline. Statistically significant values are shown in bold. EX + WB-EMS: Voluntary exercise with WB-EMS; EX: Voluntary exercise group.

- $\quad$ Speed

The results showed a significant main effect of time $\left(p<0.001, \eta^{2} p=0.75\right)$ and interaction $\left(p=0.028, \eta^{2} p\right.$ $=0.15)$. Post-hoc tests revealed significant mean difference between pre- and post-tests of both groups (EX + WB-EMS: -1.96 s 95\% CI [-2.62, -1.30], $p_{\text {Bonferroni }}<0.001$; EX: -1.20 s 95\% CI [-1.86, -0.54$]$, $\left.p_{\text {Bonferroni }}<0.001\right)$. However, non-statistically significant between-groups differences were shown in either pre-test or post-test (pre-test: $-1.45 \mathrm{~s} 95 \%$ CI [-3.11, -0.21$], p_{\text {Bonferroni }}=0.120$; post-test: $-0.69 \mathrm{~s}$ $95 \%$ CI $\left.[-2.35,0.97], p_{\text {Bonferroni }}=1.000\right)$.

\section{- Cardiovascular endurance}

Data revealed a significant main effect of time $\left(p<0.001, \eta^{2} p=0.81\right)$. Post-hoc tests showed a significant mean difference between pre- and post-tests $\left(90.60 \mathrm{~m} \mathrm{95 \%} \mathrm{CI} \mathrm{[61.74,} \mathrm{119.46],} p_{\text {Bonferroni }}<0.001\right)$. Finally, a statistically significant interaction $\left(p<0.001, \eta^{2} p=0.68\right)$ was obtained. Post-hoc tests revealed a significant mean difference between pre- and post-tests of the EX + WB-EMS group (155.54 $\mathrm{m} \mathrm{95 \%} \mathrm{CI}$ $\left.[122.99,188.08], p_{\text {Bonferroni }}<0.001\right)$ but not in the EX group $\left(25.66 \mathrm{~m} \mathrm{95 \%} \mathrm{CI}[-6.88,58.21], p_{\text {Bonferroni }}=\right.$ $0.201)$. Statistically significant between-groups differences were shown in post-test $(-117.63 \mathrm{~m} 95 \%$ CI $\left.[-174.54,60.71], p_{\text {Bonferroni }}<0.001\right)$ but not in pre-test $\left(12.25 \mathrm{~m} \mathrm{95 \%} \mathrm{CI}[-44.66,69.16], p_{\text {Bonferroni }}=\right.$ 1.0000). (See Figure 5). 

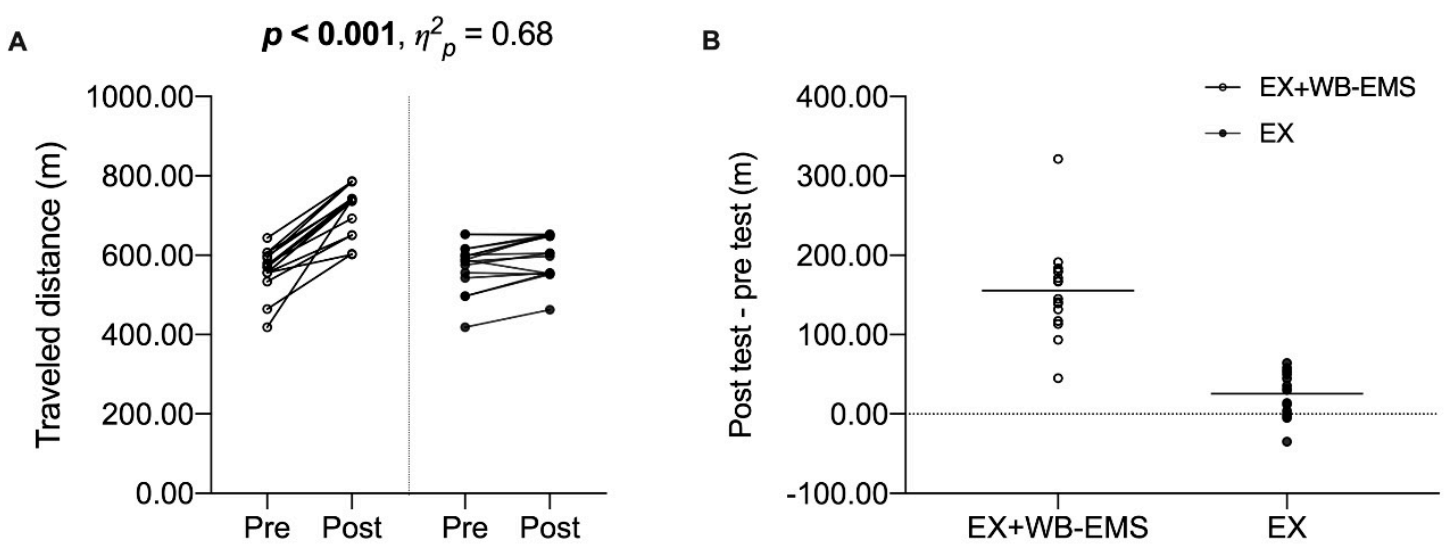

Figure 5. Scatter plots of individual values for meters traveled by both groups before and after the intervention (panel A), and individual pre-test-post-test differences of meters walked by both groups (panel B). Unfilled dots represent EX + WB-EMS group values; full dots represent EX group values. The solid lines in panel B show the mean difference. Statistically significant values are shown in bold. EX + WB-EMS: Voluntary exercise with WB-EMS; EX: Voluntary exercise group.

\section{Discussion}

To the best of our knowledge, this is the first study that aims at such a broad and multivariable analysis of the WB-EMS influence on the physical performance of healthy postmenopausal women. The WB-EMS was applied with a submaximal intensity and simultaneously to the performance of cardio and strength resistance training with medium loads. The main findings were the improvements in both groups in the variables of leg strength, arm strength, agility, and speed but with higher improvements in the EX + WB-EMS group. In addition, only the EX + WB-EMS group obtained improvements in cardiovascular endurance.

\subsection{Balance}

No changes in balance were observed after the application of WB-EMS. These findings agree with a review published in 2008, which concluded that progressive resistance training alone is not uniformly effective in improving balance, as only approximately half of the included studies (14/29) showed positive results [51]. Nevertheless, recent studies found a relationship between strength gains and static balance in older people [52-55], which makes necessary future studies that shed light on this controversy.

\subsection{Leg Strength}

Both groups showed pre-post-test increases in the development of leg strength with higher improvement in the EX + WB-EMS group, which suggests a positive effect of WB-EMS by itself. It is difficult to make a comparison of these results with those obtained in the existing literature on WB-EMS with similar populations. This is because most of the previous studies analyzed the evolution of maximum isometric force, unlike the functional orientation of the strength variable in the present study.

Kemmler et al. [25] analyzed the application of WB-EMS on 30 postmenopausal women (64.5 \pm 5.5 years). After 14 weeks of training, the authors observed significant pre-post-test differences between groups in the isometric strength of the leg extenders. This result enforces those of the present study. The same authors carried out a WB-EMS training program in which 60 sedentary women (75 \pm 4 years) participated [56]. After one year of treatment, significant pre-post-test differences were found between groups in the isometric strength of the leg extenders. This prolonged treatment had the disadvantage that the control group had long periods of inactivity, which could make the treatments not comparable, but the results of these authors show a similar trend to those obtained in the present study. However, 
we consider that any analysis of the isolated effect of the WB-EMS should guarantee the comparability of the treatments of both groups, as indicated by Pano-Rodriguez et al. [57] and so we did.

In Wolfgang Kemmler et al. [23], 67 elderly men ( $\geq 70$ years) with sarcopenic obesity received a protein supplementation. The control group did not perform any type of physical activity, and the experimental group conducted 1.5 weekly WB-EMS sessions. After 16 weeks of treatment, the authors observed significant differences between groups in the dynamic strength of the leg extenders. Similar results are shown by these authors with those obtained in the present study despite the differences in the current parameters. The authors used a noticeably greater frequency $(85 \mathrm{~Hz})$, while in the present study, we observe that $55 \mathrm{~Hz}$ is enough frequency to cause positive adaptations in force.

This is not the only study that analyzed the influence of WB-EMS on leg strength through a repetition test. Recently Schink et al. [22] analyzed the influence of 12 weeks of training with WB-EMS. They did not observe evolution in leg strength in the "Chair Stand Test". These different results could be due to the fact that, unlike the present study, their sample consisted of patients with hematological malignancies, a pathology that could limit their adaptation to strength training.

\subsection{Arms Strength}

To the best of our knowledge, the analysis of the arm flexors strength means a novelty in the study of the effects of WB-EMS. The proposed training program did show a slightly higher effect size than the EX group. There can be no doubt that the improvement in arms strength under the WB-EMS condition should be developed methodologically, considering the relationship between strength and health status of postmenopausal women. The decline in estrogen production from menopause induces a phase of rapid decrease in muscle strength $[47,58,59]$, and this training methodology seems to be appropriate in the treatment of this decrease.

\subsection{Flexibility}

Similar evolution was found in either of the groups, which means that the WB-EMS did not cause effects in flexibility. These results were expected since the training program exercises were not intended to develop flexibility in a specific way. As far as we know, no previous study has analyzed the effects of WB-EMS on flexibility, but Pérez-Bellmunt et al. [60] recently found that proprioceptive neuromuscular facilitation (PNF) stretching were more effective when combined with local electrostimulation. Based on these results, we consider the need for future studies that combine WB-EMS with flexibility-oriented exercises is raised.

\subsection{Agility}

The effect of WB-EMS on agility has been poorly studied so far, which is very curious because this training technique makes it possible to exercise in simultaneously complete kinetic chains and perform exercises with global movements during electrical stimulation [19]. Estimated means adjusted by baseline values showed better scores of the EX + WB-EMS group at post-test. We interpret that this phenomenon is due to the result of the influence of the application of the WB-EMS. Our results are enforced by Filipovic et al. [61], who also found improvements $(n=22)$. The authors measured the 15 $\mathrm{m}$ sprint with changes in direction after two days per week of WB-EMS training. In the experimental group $(n=12)$, at end of the treatment significant improvements were observed, while the control group $(n=10)$ did not experience changes. We must point out that their study sample was formed by young soccer players, but their finding enforces the existence of a positive effect of WB-EMS training on agility.

\subsection{Speed}

The EX + WB-EMS group showed better improvement in speed gait than the EX group. This suggests that WB-EMS training did cause adaptations by itself. In the aforementioned study by Kemmler et al. [23], they found differences between groups in the usual speed of walking along $10 \mathrm{~m}$. 
We must point out that in this case, the participants were not required to walk as fast as possible, but their results show the same tendency. Taking into account that the walking movement was done under the $7 \mathrm{~Hz}$ current in our training program, future interventions in which the walking superimposed current were near $50 \mathrm{~Hz}$ could be of interest. This frequency may enhance the strength in a more specific way [42], providing better improvements in the walking-fast skill.

\subsection{Cardiovascular Endurance}

Pre-post-test differences were observed in the 6 min walk test in the EX + WB-EMS group only, which suggests the existence of a positive impact of the 10-week WB-EMS training on the cardiovascular resistance of older women. Given that the aging and growth of the population resulted in an increase in global cardiovascular deaths in Europe [62], we can consider this as an interesting advance in the field of health and physical activity. This result is in accordance with what was obtained in the same test by Schink et al. [28], which reinforces the conclusions drawn here.

The improvements in cardiovascular system performance found in the present study could be explained from a physiological perspective by Filipovic et al. [63], who observed in elite soccer players positive effects of WB-EMS on the deformability of red blood cells, an important factor in the distribution of $\mathrm{O} 2$ to muscle tissue. Amaro et al. [64] observed a significant increase in VO2max and aerobic and anaerobic thresholds after a 6-week periodized WB-EMS training. Their sample was formed by young athletes, but we consider it interesting to mention the results of this study, taking into account that thresholds are very reliable markers of cardiovascular system health [65]. The increase in the values of these physiological parameters as a result of cardiovascular work with WB-EMS could be related to the improvements found in the "6-Minute Walk Test".

\subsection{Study Limitations}

This study has remarkable strengths, such as (1) the extensive analysis of physical performance through the analysis of numerous variables, (2) the realization of the same volume of voluntary training in both groups, and (3) 100\% of the participation of the sample in the sessions. But there are certain limitations that can be taken into consideration. First, a nutritional control of the sample was not carried out throughout the treatment. The importance of protein intake in strength training has been established [66], which could have confused the results. Groups were different at baseline for age, which could have influenced the results observed in this study. In our opinion, given the experimental group was slightly older, it could have prejudiced its adaptations reducing the isolate effects of WB-EMS as it is established [31]. Finally, to estimate the maximum intensity at which the participants could be electrostimulated, a pain threshold test was performed. This could be a parameter that has an excessive subjectivity, so we cannot categorically state that the intensity at which the current was applied was that required to cause adaptations.

\subsection{Practical Applications}

Under the supervision of a physical activity technician, the proposed training program based on superimposed WB-EMS could be suitable for postmenopausal women who find it difficult to carry out continuous physical exercise. It would be an adequate methodology to develop their aerobic resistance, as well as its functional capacity. In this way, due to this physical fitness enhancement, they would reduce their risk of falls [67], their cardiovascular deterioration, and their dependence, what would improve their quality of life.

\subsection{Future Proposals}

In the future, WB-EMS studies with postmenopausal women could be done with larger samples and longer interventions, as well as different frequencies and exercises. 


\section{Conclusions}

The proposed 10-week training program of strength and aerobic exercise with superimposed WB-EMS with $55 \mathrm{~Hz}$ and $7 \mathrm{~Hz}$ seems to provide additional adaptations in dynamic leg strength, gait speed, agility, and cardiovascular endurance. It does not show a favorable effect on the development of balance and flexibility of post-menopausal women.

Supplementary Materials: The spreadsheet is available at https:/osf.io (Effects of whole-body electromyostimulatin on physical fitness in postmenopausal women: a randomized controlled trial).

Author Contributions: Conceptualization, A.P.-R.; methodology, A.P.-R. and J.R.-M.; formal analysis, J.V.B.-G. and V.H.-G; investigation, V.H.-G.; resources, A.P.-R.; data curation, J.V.B.-G.; writing-original draft preparation, A.P.-R.; writing - review and editing, A.P.-R. and J.V.B.-G.; supervision, J.R.-M.; project administration, J.R.-M. All authors have read and agreed to the published version of the manuscript.

Funding: This study was funded by the non-profit organization: Institut de Desenvolupament Social i Territorial. Universitat de Lleida. The name of this project is "Active aging, quality of live and intergenerational relationships". Grant INDEST2016.

Acknowledgments: We thank the Ekke de Lleida gym for the transfer of its material and facilities for the realization of this study and to Wiemspro S.L. for its logistic support.

Conflicts of Interest: The authors declare no conflict of interest.

\section{References}

1. Kaushal, N.; Langlois, F.; Hagger, M.S.; Bherer, L. Investigating dose-Response effects of multimodal exercise programs on health-related quality of life in older adults. Clin. Interv. Aging 2019, 14, $209-217$. [CrossRef] [PubMed]

2. Nelson, M.E.; Rejeski, W.J.; Blair, S.N.; Duncan, P.W.; Judge, J.O.; King, A.C.; Macera, C.A.; Castaneda-Sceppa, C. Physical activity and public health in older adults: Recommendation from the American College of Sports Medicine and the American Heart Association. Med. Sci. Sports Exerc. 2007, 39, 1435-1445. [CrossRef] [PubMed]

3. Chodzko-Zajko, W.J.; Proctor, D.N.; Fiatarone Singh, M.A.; Minson, C.T.; Nigg, C.R.; Salem, G.J.; Skinner, J.S. Exercise and physical activity for older adults. Med. Sci. Sports Exerc. 2009, 41, 1510-1530. [CrossRef] [PubMed]

4. Pedersen, B.K. The Physiology of Optimizing Health with a Focus on Exercise as Medicine. Annu. Rev. Physiol. 2019, 81, 607-627. [CrossRef]

5. Orkaby, A.R.; Forman, D.E. Physical activity and CVD in older adults: An expert's perspective. Expert Rev. Cardiovasc. Ther. 2018, 16, 1-10. [CrossRef]

6. Bondarev, D.; Laakkonen, E.K.; Finni, T.; Kokko, K.; Kujala, U.M.; Aukee, P.; Kovanen, V.; Sipila, S. Physical performance in relation to menopause status and physical activity. Menopause 2018, 25, 1432-1441. [CrossRef]

7. Abdulnour, J.; Doucet, E.; Brochu, M.; Lavoie, J.-M.; Strychar, I.; Rabasa-Lhoret, R.; Prud'homme, D. The effect of the menopausal transition on body composition and cardiometabolic risk factors: A Montreal-Ottawa New Emerging Team group study. Menopause 2012, 19, 760-767. [CrossRef]

8. Guthrie, J.R.; Dennerstein, L.; Dudley, E.C. Weight gain and the menopause: A 5-year prospective study. Climacteric 1999, 2, 205-211. [CrossRef]

9. Hodson, L.; Harnden, K.; Banerjee, R.; Real, B.; Marinou, K.; Karpe, F.; Fielding, B.A. Lower resting and total energy expenditure in postmenopausal compared with premenopausal women matched for abdominal obesity. J. Nutr. Sci. 2014, 3, e3. [CrossRef]

10. Duval, K.; Prud'homme, D.; Rabasa-Lhoret, R.; Strychar, I.; Brochu, M.; Lavoie, J.-M.; Doucet, E. Effects of the menopausal transition on energy expenditure: A MONET Group Study. Eur. J. Clin. Nutr. 2013, 67, 407-411. [CrossRef]

11. Lohne-Seiler, H.; Torstveit, M.K.; Anderssen, S.A. Training: Effects on Muscle Strength and Power in the Elderly. J. Aging Phys. Act. 2013, 21, 51-70. [CrossRef] [PubMed]

12. Vechin, F.C.; Libardi, C.A.; Conceicao, M.S.; Damas, F.R.; Lixandrao, M.E.; Berton, R.P.B.; Tricoli, V.A.A.; Roschel, H.A.; Cavaglieri, C.R.; Chacon-Mikahil, M.P.T.; et al. Comparisons between low-intensity resistance 
training with blood flow restriction and high-intensity resistance training on quadriceps muscle mass and strength in elderly. J. Strength Cond. Res. 2015, 29, 1071-1076. [CrossRef] [PubMed]

13. Narici, M.V.; Reeves, N.D.; Morse, C.I.; Maganaris, C.N. Muscular adaptations to resistance exercise in the elderly. J. Musculoskelet. Neuronal Interact. 2004, 4, 161-164. [PubMed]

14. Rice, J.; Keogh, J.W.L. Power Training: Can it Improve Functional Performance in Older Adults? A Systematic Review. Int. J. Exerc. Sci. 2009, 2, 131-151.

15. Park, J.; Han, D. Effects of high intensity aerobic exercise on treadmill on maximum-expiratory lung capacity of elderly women. J. Phys. Ther. Sci. 2017, 29, 1454-1457. [CrossRef]

16. Osuka, Y.; Matsubara, M.; Hamasaki, A.; Hiramatsu, Y.; Ohshima, H.; Tanaka, K. Development of low-volume, high-intensity, aerobic-type interval training for elderly Japanese men: A feasibility study. Eur. Rev. Aging Phys. Act. 2017, 14, 1-8. [CrossRef]

17. Li, K.; Fang, Y.; Zhou, Y.; Liu, H. Non-Invasive Stimulation-Based Tactile Sensation for Upper-Extremity Prosthesis: A Review. IEEE Sens. J. 2017, 17, 2625-2635. [CrossRef]

18. Zhou, Y.; Fang, Y.; Gui, K.; Li, K.; Zhang, D.; Liu, H. SEMG Bias-Driven Functional Electrical Stimulation System for Upper-Limb Stroke Rehabilitation. IEEE Sens. J. 2018, 18, 6812-6821. [CrossRef]

19. Filipovic, A.; Kleinoder, H.; Dormann, U.; Mester, J.; Klein Der, H.; Rmann, U.D.; Mester, J. Electromyostimulation-a Systematic Review of the Effects of Different Electromyostimulation Methods on Selected Strength Parameters in Trained and Elite Athletes. J. Strength Cond. Res. 2012, 26, 2600-2614. [CrossRef]

20. Wiemspro-Electrostimulation for Fitness. Available online: https://wiemspro.com/?lang=es (accessed on 22 July 2019).

21. Kemmler, W.; Teschler, M.; Weißenfels, A.; Bebenek, M.; Fröhlich, M.; Kohl, M.; von Stengel, S.; Weissenfels, A.; Bebenek, M.; Frohlich, M.; et al. Effects of whole-body electromyostimulation versus high-intensity resistance exercise on body composition and strength: A randomized controlled study. Evid.-Based Complement. Altern. Med. 2016, 2016, 9236809. [CrossRef]

22. Schink, K.; Reljic, D.; Herrmann, H.J.; Meyer, J.; Mackensen, A.; Neurath, M.F.; Zopf, Y. Whole-Body Electromyostimulation Combined With Individualized Nutritional Support Improves Body Composition in Patients with Hematological Malignancies-A Pilot Study. Front. Physiol. 2018, 9, 1-15. [CrossRef] [PubMed]

23. Kemmler, W.; Grimm, A.; Bebenek, M.; Kohl, M.; Von Stengel, S. Effects of Combined Whole-Body Electromyostimulation and Protein Supplementation on Local and Overall Muscle/Fat Distribution in Older Men with Sarcopenic Obesity: The Randomized Controlled Franconia Sarcopenic Obesity (FranSO) Study. Calcif. Tissue Int. 2018, 103, 266-277. [CrossRef] [PubMed]

24. Kemmler, W.; Bebenek, M.; Engelke, K.; von Stengel, S. Impact of whole-body electromyostimulation on body composition in elderly women at risk for sarcopenia: The Training and ElectroStimulation Trial (TEST-III). Age (Dordr.). 2014, 36, 395-406. [CrossRef] [PubMed]

25. Kemmler, W.; Schliffka, R.; Mayhew, J.L.; von Stengel, S. Effects of whole-body electromyostimulation on resting metabolic rate, body composition, and maximum strength in postmenopausal women: the Training and ElectroStimulation Trial. J. Strength Cond. Res. 2010, 24, 1880-1887. [CrossRef] [PubMed]

26. von Stengel, S.; Bebenek, M.; Engelke, K.; Kemmler, W. Whole-body electromyostimulation to fight osteopenia in elderly females: The randomized controlled training and electrostimulation trial (TEST-III). J. Osteoporos. 2015, 2015, 643520. [CrossRef]

27. Kemmler, W.; Teschler, M.; Weissenfels, A.; Bebenek, M.; von Stengel, S.; Kohl, M.; Freiberger, E.; Goisser, S.; Jakob, F.; Sieber, C.; et al. Whole-body electromyostimulation to fight sarcopenic obesity in community-dwelling older women at risk. Resultsof the randomized controlled FORMOsA-sarcopenic obesity study. Osteoporos. Int. 2016, 27, 3261-3270. [CrossRef]

28. Schink, K.; Herrmann, H.J.; Schwappacher, R.; Meyer, J.; Orlemann, T.; Waldmann, E.; Wullich, B.; Kahlmeyer, A.; Fietkau, R.; Lubgan, D.; et al. Effects of whole-body electromyostimulation combined with individualized nutritional support on body composition in patients with advanced cancer: a controlled pilot trial. BMC Cancer 2018, 18, 886. [CrossRef]

29. Kemmler, W.; Weissenfels, A.; Teschler, M.; Willert, S.; Bebenek, M.; Shojaa, M.; Kohl, M.; Freiberger, E.; Sieber, C.; von Stengel, S. Whole-body electromyostimulation and protein supplementation favorably affect sarcopenic obesity in community-dwelling older men at risk: The randomized controlled FranSO study. Clin. Interv. Aging 2017, 12, 1503-1513. [CrossRef] 
30. Amaro-Gahete, F.J.; De-la-O, A.; Sanchez-Delgado, G.; Robles-Gonzalez, L.; Jurado-Fasoli, L.; Ruiz, J.R.; Gutierrez, A. Functional Exercise Training and Undulating Periodization Enhances the Effect of Whole-Body Electromyostimulation Training on Running Performance. Front. Physiol. 2018, 9, 720. [CrossRef]

31. Von Stengel, S.; Kemmler, W. Trainability of leg strength by whole-body electromyostimulation during adult lifespan: A study with male cohorts. Clin. Interv. Aging 2018, 13, 2495-2502. [CrossRef]

32. Muñoz-arribas, A.; Mata, E.; Pedrero-chamizo, R.; Espino, L.; Gusi, N.; Villa, G.; Gonzalez-gross, M.; Casajús, J.A.; Ara, I.; Gómez-cabello, A. Obesidad sarcopénica y condición física en octogenarios; proyecto multicéntrico EXERNET. Nutr. Hosp. 2013, 28, 1877-1883. [PubMed]

33. Schulz, K.F.; Altman, U.G.; Moher, D. CONSORT 2010 Statement. Obstet. Gynecol. 2010, 115, $1063-1070$. [CrossRef] [PubMed]

34. Moniker Privacy Services Random Team Generator-Split a List into Random Groups. Available online: https://www.randomlists.com/team-generator (accessed on 26 November 2019).

35. Sjöström, M.; Oja, P.; Hagströmer, M.; Smith, B.J.; Bauman, A. Health-enhancing physical activity across European Union countries: The Eurobarometer study. J. Public Health (Bangkok) 2006, 14, 291-300. [CrossRef]

36. Kovanen, V.; Aukee, P.; Kokko, K.; Finni, T.; Tarkka, I.M.; Tammelin, T.; Kujala, U.M.; Sipilä, S.; Laakkonen, E.K. Design and protocol of Estrogenic Regulation of Muscle Apoptosis (ERMA) study with 47 to 55-year-old women's cohort: Novel results show menopause-related differences in blood count. Menopause 2018, 25, 1020-1032. [CrossRef] [PubMed]

37. Aragão-Santos, J.C.; De Resende-Neto, A.G.; Nogueira, A.C.; Feitosa-Neta, M.D.L.; Brandão, L.H.A.; Chaves, L.M.D.S.; Da Silva-Grigoletto, M.E.; Feitosa-Neta, M.L. The effects of functional and traditional strength training on different strength parameters of elderly women: A randomized and controlled trial. $J$. Sports Med. Phys. Fit. 2019, 59, 380-386. [CrossRef] [PubMed]

38. Gonzalez-Badillo, J.J.; Sanchez-Medina, L. Movement velocity as a measure of loading intensity in resistance training. Int. J. Sports Med. 2010, 31, 347-352. [CrossRef] [PubMed]

39. Wirtz, N.; Wahl, P.; Kleinöder, H.; Wechsler, K.; Achtzehn, S.; Mester, J. Acute metabolic, hormonal, and psychological responses to strength training with superimposed EMS at the beginning and the end of a 6 week training period. J. Musculoskelet. Neuronal Interact. 2015, 15, 325-332.

40. Reed, J.L.; Pipe, A.L. The talk test: A useful tool for prescribing and monitoring exercise intensity. Curr. Opin. Cardiol. 2014, 29, 475-480. [CrossRef]

41. Borg, G. Perceived exertion as an indicator of somatic stress. Scand. J. Rehabil. Med. 1970, 2, 92-98.

42. Filipovic, A.; Klein Der, H.; Rmann, U.D.; Mester, J. Electromyostimulation-A Systematic Review of the Influence of Training Regimens and Stimulation Parameters on Effectiveness in Electromyostimulation Training of Selected Strength Parameters. J. Strength Cond. Res. 2011, 25, 3218-3238. [CrossRef]

43. Doucet, B.M.; Lam, A.; Griffin, L. Neuromuscular electrical stimulation for skeletal muscle function. Yale J. Biol. Med. 2012, 85, 201-215. [PubMed]

44. A Guide to the Use of Electrical Stimulation in Pediatric Nurodisbility. Association of Paediatric Chartered Physiotherapists. Available online: https://apcp.csp.org.uk/content/guide-use-electrical-stimulationpaedaitric-neurodisability (accessed on 19 December 2019).

45. Deley, G.; Babault, N. Could low-frequency electromyostimulation training be an effective alternative to endurance training? An overview in one adult. J. Sport. Sci. Med. 2014, 13, 444-450.

46. Petrofsky, J. The effect of the subcutaneous fat on the transfer of current through skin and into muscle. Med. Eng. Phys. 2008, 30, 1168-1176. [CrossRef] [PubMed]

47. Sirola, J.; Rikkonen, T. Muscle performance after the menopause. J. Br. Menopause Soc. 2005, 11, 45-50. [CrossRef]

48. Sagarra-Romero, L.; Vicente-Rodriguez, G.; Pedrero-Chamizo, R.; Vila-Maldonado, S.; Gusi, N.; Villa-Vicente, J.G.; Espino, L.; Gonzalez-Gross, M.; Casajus, J.A.; Ara, I.; et al. Is Sitting Time Related with Physical Fitness in Spanishelderly Population? The EXERNET Multicenter Study. J. Nutr. Health Aging 2019, 23, 401-407. [CrossRef]

49. Vincent, W.J.; Weir, J.P. Statistics in Kinesiology; Human Kinetics: Champaign, IL, USA, 2012; ISBN 9781450402545.

50. Field, A. Discovering Statistics Using IBM SPSS Statistics; SAGE Publications Ltd.: Thousand Oaks, CA, USA, 2017; ISBN 9781526419521. 
51. Orr, R.; Raymond, J.; Fiatarone Singh, M. Efficacy of progressive resistance training on balance performance in older adults: A systematic review of randomized controlled trials. Sports Med. 2008, 38, 317-343. [CrossRef]

52. Marques, E.A.; Figueiredo, P.; Harris, T.B.; Wanderley, F.A.; Carvalho, J. Are resistance and aerobic exercise training equally effective at improving knee muscle strength and balance in older women? Arch. Gerontol. Geriatr. 2017, 68, 106-112. [CrossRef]

53. Gonzalez, A.M.; Mangine, G.T.; Fragala, M.S.; Stout, J.R.; Beyer, K.S.; Bohner, J.D.; Emerson, N.S.; Hoffman, J.R. Resistance training improves single leg stance performance in older adults. Aging Clin. Exp. Res. 2014, 26, 89-92. [CrossRef]

54. Joshua, A.M.; D’Souza, V.; Unnikrishnan, B.; Mithra, P.; Kamath, A.; Acharya, V.; Venugopal, A. Effectiveness of progressive resistance strength training versus traditional balance exercise in improving balance among the elderly - a randomised controlled trial. J. Clin. Diagn. Res. 2014, 8, 98-102. [CrossRef]

55. Lustosa, L.P.; Silva, J.P.; Coelho, F.M.; Pereira, D.S.; Parentoni, A.N.; Pereira, L.S.M. Impact of resistance exercise program on functional capacity and muscular strength of knee extensor in pre-frail community-dwelling older women: A randomized crossover trial. Rev. Bras. Fisioter. 2011, 15, 318-324. [CrossRef]

56. Kemmler, W.; von Stengel, S. Whole-body electromyostimulation as a means to impact muscle mass and abdominal body fat in lean, sedentary, older female adults: Subanalysis of the TEST-III trial. Clin. Interv. Aging 2013, 8, 1353-1364. [CrossRef] [PubMed]

57. Pano-Rodriguez, A.; Beltran-Garrido, J.V.; Hernandez-Gonzalez, V.; Reverter-Masia, J. Effects of whole-body electromyostimulation on health and performance: A systematic review. BMC Complement. Altern. Med. 2019, 19, 87. [CrossRef] [PubMed]

58. Asikainen, T.-M.; Kukkonen-Harjula, K.; Miilunpalo, S. Exercise for health for early postmenopausal women: a systematic review of randomised controlled trials. Sports Med. 2004, 34, 753-778. [CrossRef] [PubMed]

59. Pollanen, E.; Sipila, S.; Alen, M.; Ronkainen, P.H.A.; Ankarberg-Lindgren, C.; Puolakka, J.; Suominen, H.; Hamalainen, E.; Turpeinen, U.; Konttinen, Y.T.; et al. Differential influence of peripheral and systemic sex steroids on skeletal muscle quality in pre- and postmenopausal women. Aging Cell 2011, 10, 650-660. [CrossRef] [PubMed]

60. Perez-Bellmunt, A.; Casasayas, O.; Navarro, R.; Simon, M.; Martin, J.C.; Perez-Corbella, C.; Blasi, M.; Ortiz, S.; Alvarez, P.; Pacheco, L. Effectiveness of low-frequency electrical stimulation in proprioceptive neuromuscular facilitation techniques in healthy males: a randomized controlled trial. J. Sports Med. Phys. Fitness 2019, 59, 469-475. [CrossRef] [PubMed]

61. Filipovic, A.; Grau, M.; Kleinoeder, H.; Zimmer, P.; Hollmann, W.; Bloch, W. Effects of a Whole-Body Electrostimulation Program on Strength, Sprinting, Jumping, and Kicking Capacity in Elite Soccer Players. J. Sport. Sci. Med. 2016, 15, 639-648.

62. Roth, G.A.; Forouzanfar, M.H.; Moran, A.E.; Barber, R.; Nguyen, G.; Feigin, V.L.; Naghavi, M.; Mensah, G.A.; Murray, C.J.L. Demographic and epidemiologic drivers of global cardiovascular mortality. N. Engl. J. Med. 2015, 372, 1333-1341. [CrossRef]

63. Filipovic, A.; Kleinoder,H.; Pluck, D.; Hollmann, W.; Bloch, W.; Grau, M. Influence of Whole-Body Electrostimulation on Human Red Blood Cell Deformability. J. Strength Cond. Res. 2015, 29, 2570-2578. [CrossRef]

64. Amaro-Gahete, F.J.; De-la-O, A.; Sanchez-Delgado, G.; Robles-Gonzalez, L.; Jurado-Fasoli, L.; Ruiz, J.R. Whole-Body Electromyostimulation Improves Performance-Related Parameters in Runners. Front. Physiol. 2018, 9, 1576. [CrossRef]

65. Makar, O.; Siabrenko, G. Influence of physical activity on cardiovascular system and prevention of cardiovascular diseases (review). Georgian Med. News 2018, 285, 69-74.

66. Morton, R.W.; Murphy, K.T.; Mckellar, S.R.; Schoenfeld, B.J.; Henselmans, M.; Helms, E.; Aragon, A.A.; Devries, M.C.; Banfield, L.; Krieger, J.W.; et al. A systematic review, meta-analysis and meta- regression of the effect of protein supplementation on resistance training-induced gains in muscle mass and strength in healthy adults. Br. J. Sports Med. 2018, 52, 376-384. [CrossRef] [PubMed]

67. Zhao, Y.; Chung, P.-K. Differences in Functional Fitness Among Older Adults with and Without Risk of Falling. Asian Nurs. Res. (Korean. Soc. Nurs. Sci). 2016, 10, 51-55. [CrossRef] [PubMed]

(C) 2020 by the authors. Licensee MDPI, Basel, Switzerland. This article is an open access article distributed under the terms and conditions of the Creative Commons Attribution (CC BY) license (http://creativecommons.org/licenses/by/4.0/). 